\title{
PENERAPAN MODEL IS-DEMATEL DALAM ANALISIS KUALITAS LAYANAN RESTORAN SOLARIA DI JAKARTA TIMUR
}

\author{
${ }^{1}$ Ronald Sukwadi \\ ${ }^{1}$ Laboratorium Inovasi Sistem Industri, Program Studi Teknik Industri, Universitas Katolik Indonesia Atma Jaya \\ Jl. Jend. Sudirman No.51, Karet Semanggi, Kecamatan Setiabudi, Kota Jakarta Selatan, Jakarta 12930 \\ e-mail: ronald.sukwadi@atmajaya.ac.id
}

\begin{abstract}
The restaurant business has grown rapidly over time. To be able to compete with other restaurants, restaurant management must improve service quality so that customers can satisfied and loyal. This study aims to measure customer satisfaction toward the services quality of Solaria restaurant by using the integration model of the Importance-Satisfaction Model (IS) and Laboratory Decision Making and Evaluation Laboratory (DEMATEL). The IS model is used to classify service quality attributes that must be prioritized for improvement, while DEMATEL is used to understand the relationships between attributes that must be improved. The IS diagram shows that there are 3 attributes in the first quadrant, 4 attributes in the second quadrant, 8 attributes in the third quadrant, and 3 attributes in the fourth quadrant. The service attributes are then further analyzed in the DEMATEL model. From the results of the IS-DEMATEL model, it is obtained the priority sequence that needs to be improved by the restaurant. The main priority for repairs is a clean dining room, while the last priority is an interesting food menu.
\end{abstract}

Key words : Service quality; DINESERV; Importance-Satisfaction Model (IS); Decision Making Trial and Evaluation Laboratory (DEMATEL)

\begin{abstract}
Abstrak
Bisnis restoran telah berkembang dengan pesat seiring berjalannya waktu. Untuk dapat bersaing dengan restoran lainnya, manajemen restoran harus meningkatkan kualitas layanan layanan agar pelanggan puas dan loyal. Penelitian ini bertujuan untuk mengukur kepuasan pelanggan terhadap kualitas layanan restoran Solaria dengan menggunakan integrasi model Importance-Satisfaction Model (IS) dan Decision Making Trial and Evaluation Laboratory (DEMATEL). Model IS digunakan untuk menggolongkan atribut kualitas layanan yang harus diprioritaskan untuk dilakukan perbaikan, sedangkan DEMATEL digunakan untuk mengetahui hubungan antar atribut yang harus diperbaiki. Dalam diagram IS terdapat 3 atribut dalam kuadran pertama, 4 atribut dalam kuadran kedua, 8 atribut dalam kuadran ketiga, dan 3 atribut dalam kuadran keempat. Atribut layanan tersebut kemudian dianalisis lebih lanjut pada model DEMATEL. Dari hasil model IS-DEMATEL diperoleh urutan peringkat prioritas atribut yang perlu dilakukan perbaikan oleh pihak restoran. Prioritas utama perbaikan adalah ruang makan yang bersih, sedangkan prioritas terakhir adalah menu makanan yang menarik.
\end{abstract}

Kata kunci : Kualitas Layanan; DINESERV; Importance-Satisfaction Model (IS); dan Decision Making Trial and Evaluation Laboratory (DEMATEL)

\section{PENDAHULUAN}

Perkembangan ekonomi di Indonesia telah berkembang dengan pesat, khususnya dapat dilihat dibidang bisnis makanan dan minuman. Makanan dan minuman merupakan kebutuhan primer manusia yang harus dipenuhi setiap harinya. Oleh karena itu, mulai banyak orang yang berinvestasi dengan membuka restoran. Seperti yang disampaikan Adhi S Lukman, Ketua Umum Gabungan Pengusaha Makanan dan Minuman Indonesia bahwa dengan populasi mencapai lebih dari 250 juta orang, Indonesia merupakan pasar yang menguntungkan bagi produsen makanan dan minuman. Di mana industri makanan dan minuman adalah sektor dengan kontribusi terbesar ekonomi Indonesia, yaitu 5,5 persen produk domestik bruto nasional dan 31 persen produk domestik bruto industri pengolahan nonmigas. Hal ini ditunjukkan pada kuartal II 2016, industri ini menunjukkan peningkatan signifikan, terutama dengan ekspektasi mencapai kenaikan 8 persen. (www.tribunnews.com). Selain itu, menurut Dirjen Industri Agro Kementerian Perindustrian Panggah Susanto pada acara CEO Gathering Gabungan Pengusaha Makanan dan Minuman Seluruh Indonesia (GAPMMI), di Jakarta bahwa industri makanan dan minuman menduduki posisi strategis dalam penyediaan produk siap saji yang aman, bergizi dan 
bermutu. Selain itu, industri makanan dan minuman nasional terus menunjukkan kinerja positif dengan tumbuh mencapai 9,82 persen atau sebesar Rp 192,69 triliun pada triwulan III 2016. (www.kemenperin.go.id).

Bisnis restoran di Jakarta Timur sudah semakin banyak yang menawarkan macam-macam menu dengan suasana yang mendukung. Hal ini membuat adanya persaingan dalam memenuhi keinginan pelanggan agar dapat menarik perhatiannya (Sukwadi \& Dian, 2016). Menurut Dutka (1994), kepuasan pelanggan merupakan hal yang sangat penting untuk mencapai keberhasilan dari suatu perusahaan (Sukwadi \& Gammadita, 2016). Karena itu apabila tetap ingin bertahan dan atau bahkan memenangkan persaingan perusahaan harus berorientasi pada pemenuhan kebutuhan dan keinginan pelanggan (Sukwadi \& Yang, 2014). Dengan begitu perusahaan akan mendapatkan loyalitas pelanggan. Seperti yang dikatakan oleh Lovelock (1991) bahwa tingkat kesetiaan dari para pelanggan terhadap suatu barang atau jasa merek tertentu tergantung pada beberapa faktor yaitu besarnya biaya untuk berpindah ke merek barang atau jasa yang lain, adanya kesamaan mutu, kuantitas atau layanan dari jenis barang atau jasa pengganti, adanya risiko perubahan biaya akibat barang atau jasa pengganti dan berubahnya tingkat kepuasan yang didapat dari merek baru dibanding dengan pengalaman terhadap merek sebelumnya yang pernah dipakai.

Berdasarkan hasil survey yang dilakukan Frontier Consulting Group dapat dilihat bahwa Solaria mengalami penurunan Top Brand Index pada kategori restoran cepat saji dari tahun 2012-2017. Selain itu, berdasarkan aplikasi Zomato rating yang dimiliki Restoran Solaria cukup rendah yaitu hanya dibawah 3 dan review dari pelanggan terdapat keluhan seperti layanan, kualitas makanan, harga, dan kebersihan. Oleh karena itu, perlu dilakukan pengukuran kualitas dengan menggunakan atribut dari metode DINESERV (Steven dkk., 1995) untuk menganalisis kepuasan pelanggan terhadap Restoran Solaria. Metode DINESERV telah digunakan untuk mengukur kualitas layanan di berbagai bisnis restoran, seperti yang telah dilakukan oleh Knuston dkk. (1995) dan Sukwadi dan Dian (2016).

Penelitian ini dikhususkan kepada pelanggan Restoran Solaria untuk mengetahui kualitas layanannya. Berdasarkan survey yang telah dilakukan, Restoran Solaria yang berada di Jakarta Timur yang memiliki keluhan terbanyak dan akan dilakukan analisis kepuasan pelanggan menggunakan metode Importance-Satisfaction Model (IS) yang telah digunakan dalam penelitian-penelitian sebelumnya seperti Yang (2003), Chen dkk (2006), Sukwadi dan Yang (2012), Sukwadi dan Jufina (2015), Sukwadi dan Chandra (2015), dan Sukwadi dkk. (2017). Menurut Martinez (2003), metode Importance-Satisfaction Model (IS) telah dipergunakan pada berbagai bidang kajian karena kemudahaan untuk diterapkan dan tampilan hasil analisis yang memudahkan usulan perbaikan kinerja.

Selanjutnya dilakukan analisis kepuasan pelanggan dengan melihat hubungan atribut kualitas layanan pada pihak manajemen Restoran Solaria menggunakan metode Decision Making Trial and Evaluation Laboratory (DEMATEL) yang dikembangkan oleh Gabus dkk. (1972). Menurut Varma dan Kumar (2012), keunggulan yang dimiliki metode DEMATEL yaitu adanya pendekatan sistematis untuk mengidentifikasi hubungan antar kriteria, dan bobot masing-masing untuk pengambilan keputusan. Model ini telah digunakan di berbagai penelitian untuk mengetahui hubungan antara atribut seperti yang dilakukan oleh Cheng dkk. (2012) dan Horng dkk. (2013). Dengan begitu, dengan mengintegrasikan model IS-DEMATEL dapat ditemukan peringkat prioritas terhadap faktor kualitas layanan yang perlu dilakukan perbaikan oleh Restoran Solaria.

\section{METODE PENELITIAN}

Objek dalam penelitian ini adalah Restoran Solaria yang ada di daerah Jakarta Timur dengan jumlah responden menurut teori Malhorta yaitu lima kali jumlah variabel, sehingga jumlah responden untuk metode IS adalah sebanyak 90 orang. Responden yang digunakan merupakan orang yang telah menjadi pelanggan Restoran Solaria minimal 1 kali dalam 1 tahun 
terakhir. Untuk responden metode DEMATEL sebanyak 6 orang. Responden yang digunakan merupakan pihak manajemen Restoran Solaria di wilayah Jakarta Timur.

Pengolahan data metode IS dilakukan dengan menghitung rata-rata tingkat kepuasan dan rata-rata tingkat kepentingan/harapan berdasarkan pelanggan terhadap restoran Solaria. Sehingga dihasilkan diagram Importance-Satisfaction model dengan bantuan software SPSS. Untuk pengolahan data metode DEMATEL dilakukan dengan menghitung matriks rata-rata, matriks rata-rata normalisasi, dan total hubungan matriks. Sehingga didapatkan nilai prominence dan nilai relation untuk diplotkan kedalam diagram prominence-relation yang dibuat juga menggunakan bantuan software SPSS.

\section{HASIL DAN PEMBAHASAN}

\section{A. Model IS}

Berdasarkan hasil dari kuesioner metode IS dihasilkan data tingkat kepuasan dan tingkat harapan/kepentingan kualitas layanan menurut pelanggan Restoran Solaria. Dari data tingkat kepuasan dan tingkat harapan/kepentingan dihasilkan diagram Importance-Satisfaction Model (Gambar 1).

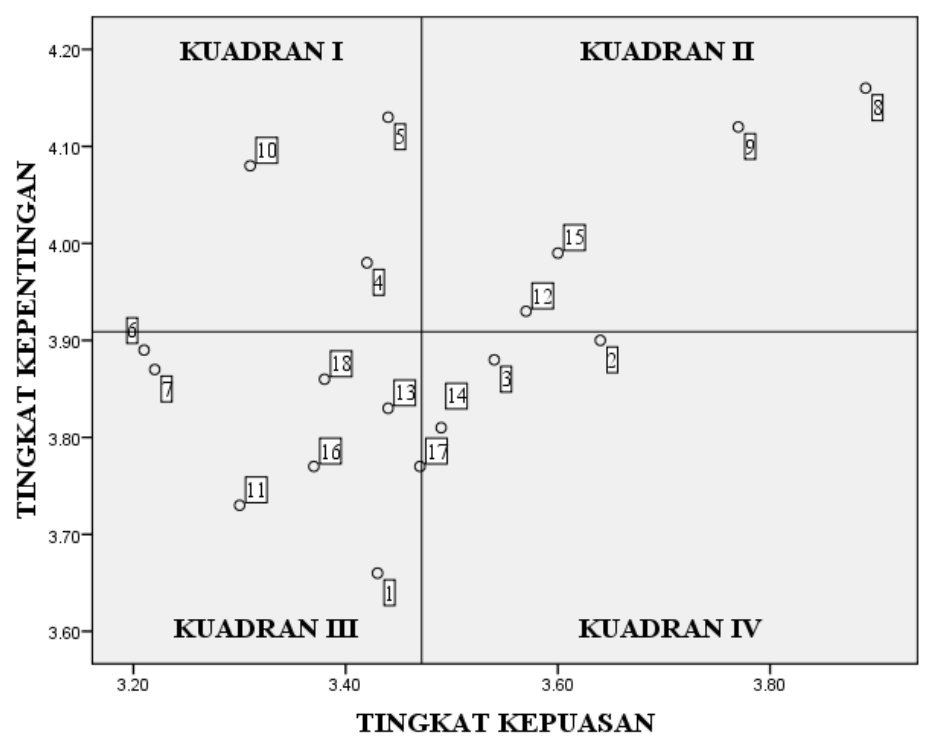

Gambar 1. Diagram Importance-Satisfaction model

Tabel 1 menyajikan atribut layanan yang telah terbagi menjadi 4 kuadran, digunakan untuk menjadi masukan atribut kuesioner metode DEMATEL yang disebarkan kepada 6 responden yang merupakan pihak manajemen Restoran Solaria. 
Tabel 1. Rekapitulasi hasil diagram IS

\begin{tabular}{|c|c|c|}
\hline Kuadran & & Pernyataan \\
\hline \multirow{3}{*}{ I } & 4 & Menu makanan yang menarik \\
\hline & 5 & Ruang makan yang bersih \\
\hline & 10 & Cepat tanggap dalam melayani \\
\hline \multirow{4}{*}{ II } & 8 & Menyediakan struk yang akurat \\
\hline & 9 & Menyediakan makanan sesuai yang dipesan \\
\hline & 12 & Memiliki staff yang dapat menjawab seluruh pertanyaan \\
\hline & 15 & Memiliki staff yang terlatih, kompeten, dan berpengalaman \\
\hline \multirow{8}{*}{ III } & 1 & Dekorasi ruang makan yang menarik dan sesuai image restoran \\
\hline & 6 & Cepat mengkoreksi kesalahan pelayanan \\
\hline & 7 & Konsisten dan dapat diandalkan dalam melayani \\
\hline & 11 & Memberikan upaya lebih untuk melayani permintaan khusus pelanggn \\
\hline & 13 & $\begin{array}{l}\text { Membuat pelanggan nyaman dan yakin dalam berurusan dengan } \\
\text { restoran }\end{array}$ \\
\hline & 16 & $\begin{array}{l}\text { Memiliki staff yang peka terhadap kebutuhan dan keinginan individu } \\
\text { pelanggan }\end{array}$ \\
\hline & 17 & Mengantisipasi kebutuhan dan keinginan individu pelanggan \\
\hline & 18 & $\begin{array}{l}\text { Memiliki staff yang bersimpati dan dapat meyakinkan jika ada sesuatu } \\
\text { yang salah }\end{array}$ \\
\hline \multirow{3}{*}{ IV } & 2 & Staff yang berpakaian rapi dan bersih \\
\hline & 3 & Buku menu yang mudah dibaca \\
\hline & 14 & $\begin{array}{l}\text { Memiliki staff yang mampu dan mau memberikan informasi tentang } \\
\text { item menu, bahan-bahan yang digunakan, dan cara menyiapkannya }\end{array}$ \\
\hline
\end{tabular}

\section{B. Model DEMATEL}

Berdasarkan hasil pengolahan kuesioner metode DEMATEL, dihasilkan nilai prominence dan nilai relation untuk masing-masing pernyataan pada kuadran metode IS untuk dibentuk dalam diagram prominence-relation. Gambar 2 menunjukkan diagram prominence-relation untuk atribut layanan pada kuadran I. Dari Tabel 2 terlihat nilai $\mathrm{r}+\mathrm{c}$ yang mewakili nilai prominence dan nilai r-c yang mewakili nilai relation. Hal ini menunjukkan terdapat hubungan pengaruh atribut satu terhadap atribut lainnya pada kuadran I. 


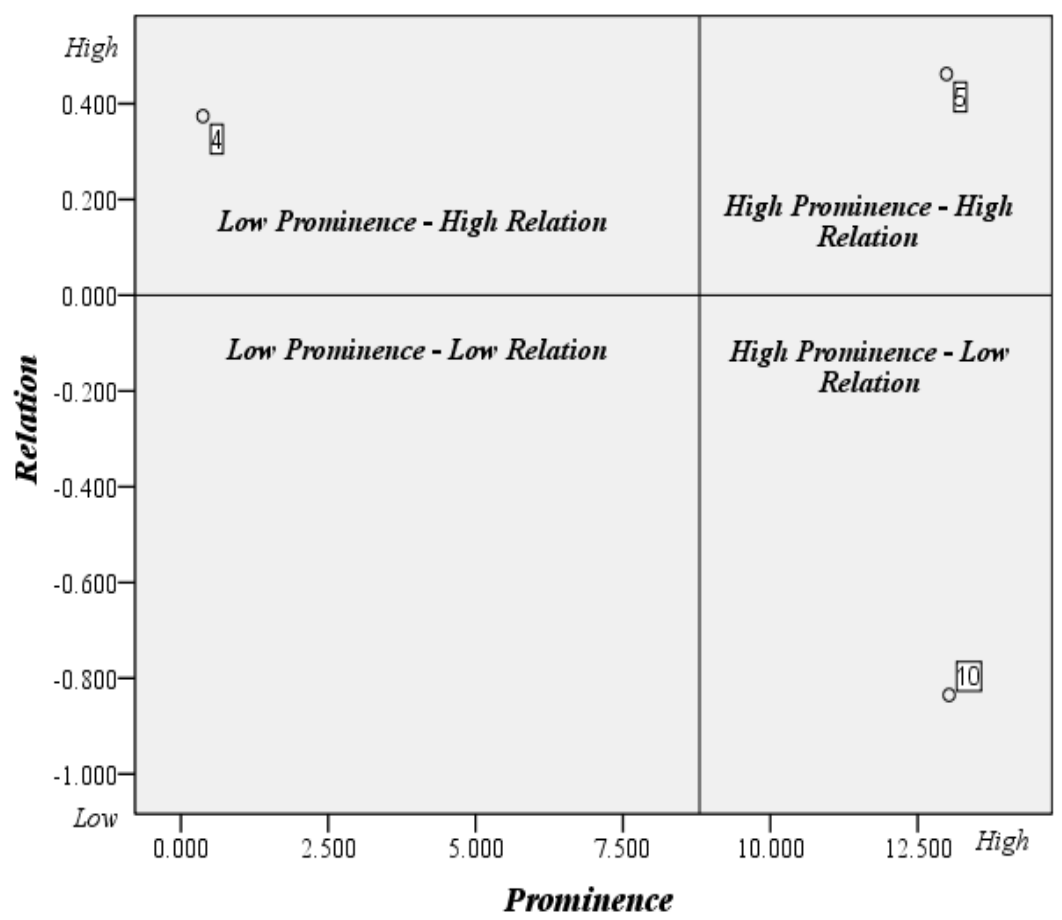

Gambar 2. Diagram Prominence-Relation atribut kuadran I

Tabel 2. Pengaruh hubungan antar atribut kuadran I

\begin{tabular}{cccc} 
Pernyataan & $\mathbf{r}+\mathbf{c}$ & $\mathbf{r}-\mathbf{c}$ & Pengaruh \\
\hline 4 & 0.374 & 0.374 & Dipengaruhi tidak secara langsung \\
5 & 12.989 & 0.462 & Mempengaruhi \\
10 & 13.033 & -0.835 & Dipengaruhi secara langsung \\
\hline
\end{tabular}

Diagram prominence-relation untuk atribut kuadran II dapat dilihat pada Gambar 3. Pada Tabel 3 terlihat nilai $\mathrm{r}+\mathrm{c}$ yang mewakili nilai prominence dan nilai $\mathrm{r}-\mathrm{c}$ yang mewakili nilai relation. Dan terdapat hubungan pengaruh atribut satu terhadap atribut lainnya pada kuadran II.

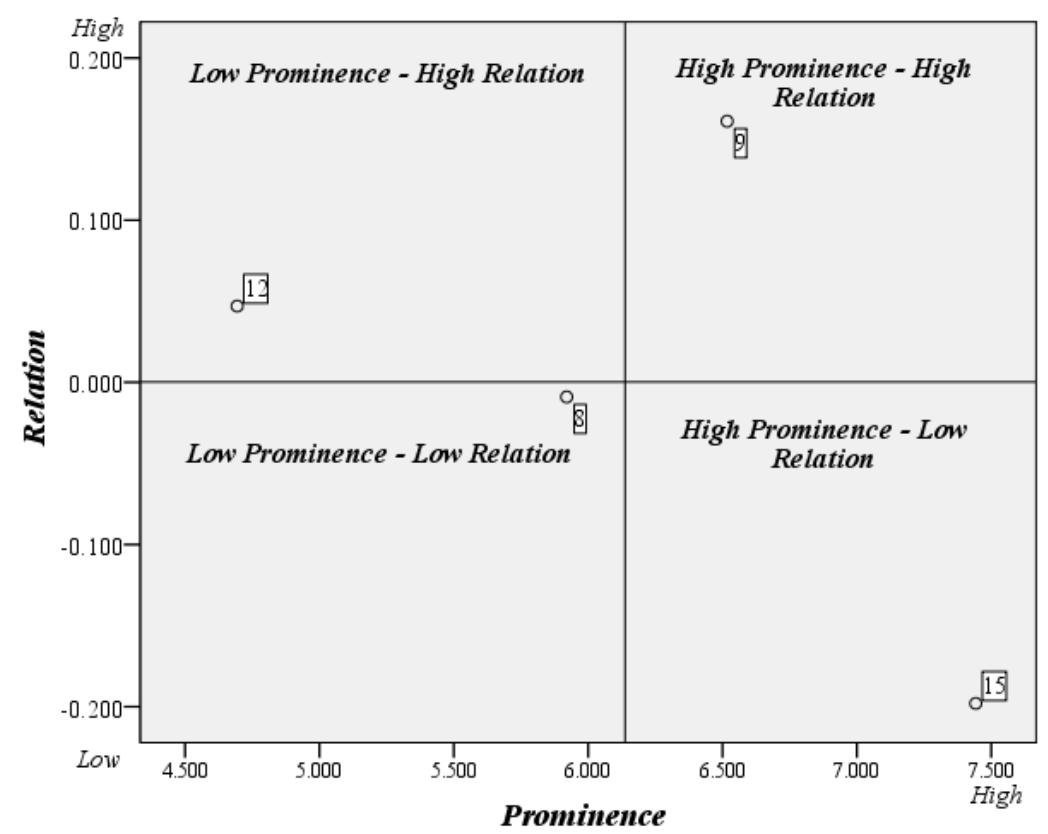

Gambar 3. Diagram Prominence-Relation atribut kuadran II 
Tabel 3. Pengaruh hubungan antar atribut kuadran II

\begin{tabular}{cccc}
\hline Pernyataan & $\mathbf{r}+\mathbf{c}$ & $\mathbf{r}-\mathbf{c}$ & Pengaruh \\
\hline 8 & 5.920 & -0.009 & Dapat diabaikan \\
9 & 6.517 & 0.161 & Mempengaruhi \\
12 & 4.694 & 0.047 & Dipengaruhi tidak secara langsung \\
15 & 7.442 & -0.198 & Dipengaruhi secara langsung \\
\hline
\end{tabular}

Diagram prominence-relation untuk atribut di kuadran III dapat dilihat pada Gambar 4 . Tabel 4 menunjukkan hubungan pengaruh suatu atribut terhadap atribut lainnya pada kuadran III.

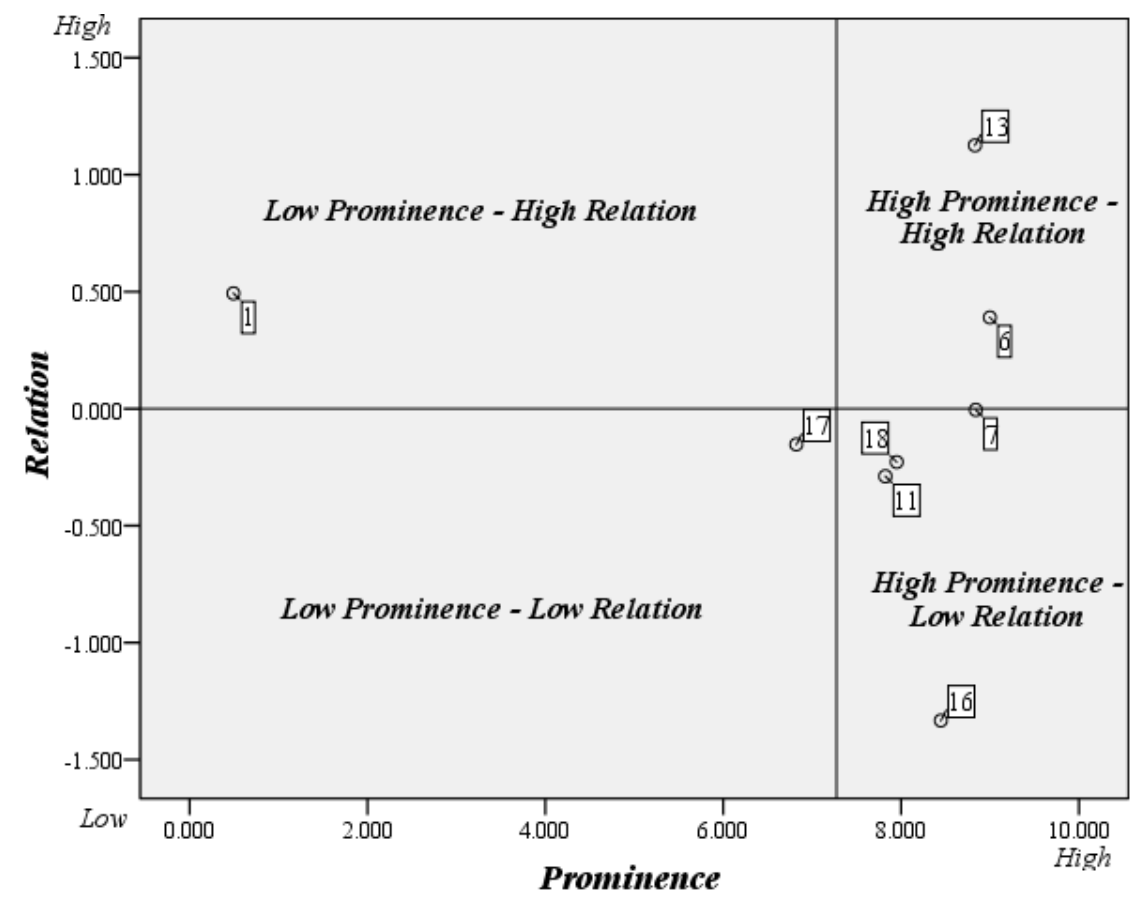

Gambar 4. Diagram Prominence-Relation atribut kuadran III

Tabel 4. Pengaruh hubungan atribut kuadran III

\begin{tabular}{cccc}
\hline Pernyataan & $\mathbf{r}+\mathbf{c}$ & $\mathbf{r}-\mathbf{c}$ & Pengaruh \\
\hline 1 & 0.493 & 0.493 & Dipengaruhi tidak secara langsung \\
6 & 8.999 & 0.390 & Mempengaruhi \\
7 & 8.840 & -0.005 & Dipengaruhi secara langsung \\
11 & 7.823 & -0.289 & Dipengaruhi secara langsung \\
13 & 8.831 & 1.126 & Mempengaruhi \\
16 & 8.447 & -1.333 & Dipengaruhi secara langsung \\
17 & 6.822 & -0.153 & Dapat diabaikan \\
18 & 7.951 & -0.228 & Dipengaruhi secara langsung \\
\hline
\end{tabular}

Gambar 5 menyajikan diagram prominence-relation untuk atribut kuadran IV. Dari Tabel 5 terlihat bahwa nilai $\mathrm{r}+\mathrm{c}$ yang mewakili nilai prominence dan nilai $\mathrm{r}-\mathrm{c}$ yang mewakili nilai relation dan terdapat hubungan pengaruh antar atribut pada kuadran IV. 


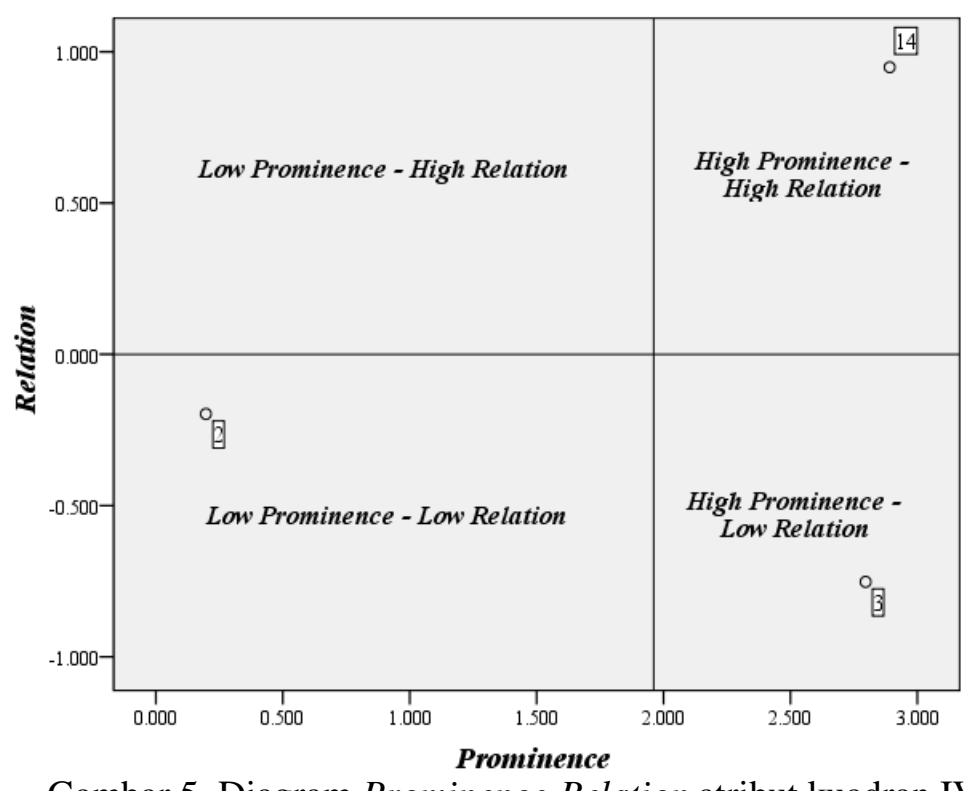

Gambar 5. Diagram Prominence-Relation atribut kuadran IV

Tabel 5. Pengaruh hubungan atribut Kuadran IV

\begin{tabular}{cccc}
\hline Pernyataan & $\mathbf{r}+\mathbf{c}$ & $\mathbf{r}-\mathbf{c}$ & Pengaruh \\
\hline 2 & 0.197 & -0.197 & Dapat diabaikan \\
3 & 2.796 & -0.752 & Dipengaruhi secara langsung \\
14 & 2.891 & 0.949 & Mempengaruhi \\
\hline
\end{tabular}

\section{Prioritas Perbaikan Hasil Integrasi Model IS-DEMATEL}

Penentuan peringkat prioritas dilihat berdasarkan kuadran pada metode IS, nilai $\mathrm{r}+\mathrm{c}$ (tingkat prominence) dan hubungan pengaruh antar atribut berdasarkan metode DEMATEL. Sehingga dihasilkan peringkat prioritas perbaikan faktor kualitas layanan pada Tabel 6. Berdasarkan Tabel 6, peringkat prioritas 1 sampai dengan 3 perlu dilakukan strategi perbaikan, karena berada pada kuadran I. Sedangkan, untuk 12 atribut sisanya yang berada pada kuadran II sampai kuadran IV perlu tetap dipertahankan kinerjanya oleh pihak restoran.

Pada prioritas ke-1, strategi perbaikan yang dapat dilakukan untuk pernyataan/atribut 5 adalah dengan membersihkan ruang makan setiap beberapa waktu sekali, seperti setiap 20 menit sekali membersihkan lantai. Selain itu, karyawan dapat langsung membersihkan meja makan yang kotor dari piring-piring makanan yang telah digunakan oleh pelanggan. Prioritas ke-2, strategi perbaikan yang dapat dilakukan membuat target waktu dalam melayani, seperti dalam menyajikan makanan dan minuman. Prioritas ke-3 dalam meningkatkan kualitas pelayanan adalah menu makanan yang menarik. Strategi perbaikan yang dapat dilakukan untuk atribut 4 adalah dengan menambahkan beberapa gambar makanan ke dalam daftar menu makanan. 
Tabel 6. Peringkat prioritas perbaikan atribut layanan Restoran Solaria

\begin{tabular}{|c|c|c|c|c|}
\hline \multirow[t]{2}{*}{ Pernyataan } & \multirow{2}{*}{$\begin{array}{l}\text { Kuadran } \\
\text { Metode IS }\end{array}$} & \multicolumn{2}{|r|}{ Dematel } & \multirow{2}{*}{$\begin{array}{c}\text { Peringkat } \\
\text { Prioritas }\end{array}$} \\
\hline & & $\mathbf{r}+\mathbf{c}$ & Pengaruh & \\
\hline 5 & I & 12.989 & Mempengaruhi & 1 \\
\hline 10 & I & 13.033 & Dipengaruhi secara langsung & 2 \\
\hline 4 & I & 0.374 & Dipengaruhi tidak secara langsung & 3 \\
\hline 9 & II & 6.517 & Mempengaruhi & 4 \\
\hline 15 & II & 7.442 & Dipengaruhi secara langsung & 5 \\
\hline 12 & II & 4.694 & Dipengaruhi tidak secara langsung & 6 \\
\hline 6 & III & 8.999 & Mempengaruhi & 7 \\
\hline 7 & III & 8.840 & Dipengaruhi secara langsung & 8 \\
\hline 18 & III & 7.951 & Dipengaruhi secara langsung & 9 \\
\hline 11 & III & 7.823 & Dipengaruhi secara langsung & 10 \\
\hline 13 & III & 8.831 & Mempengaruhi & 11 \\
\hline 16 & III & 8.447 & Dipengaruhi secara langsung & 12 \\
\hline 1 & III & 0.493 & Dipengaruhi tidak secara langsung & 13 \\
\hline 14 & IV & 2.891 & Mempengaruhi & 14 \\
\hline 3 & IV & 2.796 & Dipengaruhi secara langsung & 15 \\
\hline
\end{tabular}

Prioritas ke-4, atribut 9 dapat dipertahankan kinerjanya karena staff telah melakukan penginputan sesuai dengan pesanan pelanggan. Sehingga para koki dapat memasak sesuai makanan yang dipesan. Dan kesesuaian dalam menyajikan makanan yang dipesan pelanggan dapat dilihat dari order checker dan struck. Prioritas ke-5, atribut 15 dapat dipertahankan kinerjanya Restoran Solaria telah memberikan pelatihan kepada semua staff agar lebih berkompeten dan berpengalaman dalam menjalankan tugasnya masing-masing. Prioritas ke-6, atribut 12 dapat dipertahankan kinerjanya, karena saat pelanggan bertanya mengenai restoran, seperti mengenai makanan. Staf dapat menjawab pertanyaan pelanggan.

Prioritas ke-7, atribut 6 dapat dipertahankan kinerjanya, karena dengan sigap staff meminta maaf kepada pelanggan dan langsung memberikan penggantian terhadap sesuatu yang salah. Prioritas ke-8, atribut 7 dapat dipertahankan kinerjanya, karena pihak restoran konsisten dalam melayani kosumen. Di mana staf akan melayani dengan baik dan konsisten dari awal pelanggan masuk ke restoran, memesan makanan langsung di meja kasir, pembayaran, penyajian makanan, dan sampai menjalankan permintaan kebutuhan dan keinginan dari individu.

Prioritas ke-9, atribut 18 dapat dipertahankan kinerjanya, karena staf dapat meyakinkan jika ada sesuatu yang salah. Seperti, saat pelanggan memesan menu makanan yang sedang habis, staf akan langsung memberitahukan bahwa menu makanan yang dipesan sedang habis. Agar pelanggan dapat mengganti menu lainnya. Prioritas ke-10, atribut 11 dapat dipertahankan kinerjanya, karena pihak restoran telah melayani permintaan khusus pelanggan. Misalkan pelanggan memesan nasi goreng seafood tanpa kecap dan tanpa cabe besar, restoran akan membuat makanan sesuai dengan permintaan khusus pelanggan.

Prioritas ke-11, atribut 13 dapat dipertahankan kinerjanya, karena restoran telah memberikan kenyamanan seperti staf mengucapkan salam pembukaan pembicaraan, menegaskan kembali pesanan pelanggan, menyelesaikan transaksi pembayaran dengan benar, dan mengucapkan terima kasih diiringi harapan agar pelanggan akan kembali. Selain itu, pelanggan yakin dengan cita rasa makanan yang disediakan sesuai dengan harga yang ditawarkan. Prioritas ke-12, atribut 16 dapat dipertahankan kinerjanya, karena staf peka terhadap kebutuhan dan keinginan individu pelanggan. Seperti, saat pelanggan membawa anak kecil, staff akan menyiapkan baby chair untuk anak kecil tersebut. Prioritas ke-13, atribut 1 dapat dipertahankan kinerjanya, karena restoran telah membuat dekorasi ruang makan simple dengan adanya sedikit tanaman hijau. Dengan begitu, pelanggan akan tertarik untuk mendatangi Restoran Solaria. 
Prioritas ke-14, atribut 14 dapat dipertahankan kinerjanya, karena jika pelanggan bertanya mengenai makanan yang diolah dalam restoran staf dapat memberikan penjelasan dengan baik mengenai makanan tersebut. Prioritas terakhir, atribut 3 dapat dipertahankan kinerjanya, karena restoran telah menyediakan buku menu yang simple sehingga pelanggan dapat dengan mudah membaca tulisannya.

\section{SIMPULAN}

Berdasarkan hasil penelitian terhadap kualitas Restoran Solaria, maka dapat disimpulkan bahwa berdasarkan dimensi DINESERV terdapat 18 atribut layanan pada Restoran Solaria. Analisis model IS mengkategorikan 18 atribut layanan tersebut kedalam 4 kuadran yaitu 3 atribut pada kuadran I, 4 atribut pada kuadran II, 8 atribut pada kuadran III, dan sisanya pada kuadran IV. Hasil metode DEMATEL, menjelaskan bahwa terdapat 3 dari 18 atribut layanan dapat diabaikan karena tidak memiliki pengaruh antar atribut layanan. Integrasi metode ISDEMATEL dapat digunakan untuk menentukan prioritas perbaikan atribut layanan Restoran Solaria.

Dengan hasil penelitian yang sudah dilakukan maka dapat diberikan beberapa saran bagi pihak restoran Solaria antara lain pihak restoran Solaria sebaiknya membersihkan ruang makan setiap beberapa waktu sekali dan membiasakan staff langsung membersihkan meja kotor setelah digunakan oleh pelanggan. Hal ini dilakukan agar menjaga kebersihan ruang makan. Selain itu, pihak restoran Solaria hendaknya memberikan target waktu dalam menyajikan makanan dan minuman. Hal tersebut dilakukan agar pelanggan dapat merasa bahwa pelayanan restoran cepat tanggap dalam melayani. Pihak Restoran Solaria hendaknya menambahkan beberapa gambar makanan ke dalam daftar menu makanan agar tampilan dari menu makanan dapat lebih menarik perhatian pelanggan.

Peneliti selanjutnya diharapkan dapat menambah metode pengukuran kualitas layanan lainnya untuk dapat dibandingkan dengan hasil penelitian ini. Selain itu, wilayah penelitian bisa diperluas, tidak hanya restoran Solaria di Jakarta Timur saja.

\section{DAFTAR PUSTAKA}

Chen, S. H., Yang, C. C., Shiau, J. Y., \& Wang, H. H. (2006). The development of an employee satisfaction model for higher education. The TQM Magazine, 18(5).484-500.

Cheng, C. C., Chen, C. T., Hsu, F. S., \& Hu, H. Y. (2012). Enhancing service quality improvement strategies of fine dining restaurants: New insights from integrating a twoPhase decision-making model of IPGA and DEMATEL analysis. International Journal of Hospitality Management, 31, 1155-1166.

Dutka, A. (1994). AMA Hand Book for Customer Satisfaction. Illinois: NTC Business Book.

Fontela, E., \& Gabus, A. (1972). World Problems an Invitation to Further Thought within the Framework of DEMATEL. Geneva: Battelle Geneva Research Centre.

Horng, J. S., Liu, C. H., Chou, S. F., \& Tsai, C. Y. (2013). Creativity as a critical criterion for future restaurant space design: Developing a novel model with DEMATEL application. International Journal of Hospitality Management, 33, 96-105.

Lovelock, C. H. (1991). Service Marketing . New Jersey: Prentice-Hall Inc.

Malhortra K, N. (1993). Marketing Research An Applied Orientation (Second ed.). New Jersey: Prentice Hall International Inc.

Stevens, P., Knutson , B., \& Patton, M. (1995). DINESERV: A tool for measuring service quality in restaurants. The Cornell Hotel and Restaurant Administration Quarterly, 36(2), $56-60$.

Sukwadi, R., \& Dian, A. (2016). Analisis kualitas layanan restoran dengan menggunakan model Kano-PRCA dan AIM. Spektrum Industri, 14(1), 89-98.

Sukwadi, R., \& Yang, C. C. (2014). Determining service improvement priority in a zoological park. Journal of Industrial Engineering and Management, 7(1), 1-20 
Sukwadi, R., Inderawati, M.M.W., \& Sunarsa, K.A. 2017. Perbaikan atribut kualitas layanan Maxx Coffee shop, Jurnal Teknik \& Ilmu Komputer, 6(21), 51-62.

Sukwadi, R., \& Chandra, P. 2015. Ekspektasi penumpang terhadap kualitas layanan Bandara Internasional Soekarno-Hatta, Jurnal Teknik \& Ilmu Komputer, 4(13), 60-68.

Sukwadi, R., \& Gammadita, M.C. 2016. Analisis retensi pengunjung bioskop di Jakarta menggunakan regresi logistik multinomial, Jurnal Teknologi, 9(2), 89-97.

Sukwadi, R., \& Jufina. 2015. Penentuan prioritas perbaikan kualitas layanan TransJakarta dengan menggunakan metode IPA-PGCV, Jurnal Rekayasa Sistem Industri, 4(2), 64-69.

Sukwadi, R., \& Yang, C.C. 2012. Determining critical service attributes and appropriate improvement actions in Indonesian HEIs. Industrial Engineering \& Management Systems, $11(3), 241-254$

Varma, K., \& Kumar, K. S. (2012). Criteria analysis aiding portfolio selection using DEMATEL. Procedia Engineering, 38, 3649-3661.

Yang, C. C. (2003). Improvement actions based on the customers satisfaction survey. TQM \& Business Excellence, 14(8), 919-930. 